\title{
A EDUCAÇÃO DO NOVO MILÊNIO E A IDEOLOGIA DA TERCEIRA VIA
}

\section{EDUCATION IN THE NEW MILLENNIUM AND THE IDEOLOGY OF THE THIRD WAY}

\section{Eduard Angelo Bendrath}

\begin{abstract}
RESUMO
O conceito de Terceira Via, movimento teórico que tenta romper com a polarização entre liberalismo e socialismo, apresenta indicativos de união entre ambas correntes, através de idéias e perspectivas, tanto no campo econômico, quanto no social. A análise de sua constituição epistemológica remete a feições de cunho neoliberal com proposições sociais, caracterizada de "social-democracia" que podem, dentre outros campos, influenciar o movimento educacional no novo milênio. Dentro dessa perspectiva, esse texto visa relacionar as abordagens políticas da Terceira Via, com as propostas educacionais conclamadas pelos organismos internacionais nas últimas décadas, justificado pelo crescente interesse governamental na adoção de políticas públicas concomitantes que valorizem a participação civil e o desenvolvimento econômico. Como procedimento adotouse uma análise teórica sobre as publicações da UNESCO que fundamentam sua concepção de educação e correlacionou-os a partir da abordagem teórica da Terceira Via defendida por Anthony Giddens. Observaram-se indicativos de aproximação entre ambas as políticas, fortalecendo o discurso de um panorama educacional global alinhado ao fluxo de desenvolvimento econômico.
\end{abstract}

Palavras-chave: Terceira Via. Liberalismo. Política Internacional. Educação.

\begin{abstract}
The concept of Third Way, a theoretical movement that tries to break with the polarization between liberalism and socialism presents indications of agreement between the two ideologies through ideas and perspectives, both in the economic and social fields. The epistemological analysis of its constitution refers to features of neoliberal social propositions, characterized as "social democracy" that along with other fields influence the educational movement in the new millennium. From this perspective, this text aims to relate the policy approaches of the Third Way, with the educational proposals further urged by international organizations in recent decades, justified by increased government interest in the adoption of public policies that value civil participation and economic development. The study adopted a theoretical analysis of the UNESCO documents about the conception of education correlating them using the theoretical approach of the Third Way
\end{abstract}

\footnotetext{
* Mestre em Educação e Doutorando na área de políticas públicas e formação de professores na UNESP - Universidade Estadual Paulista Faculdade de Ciências e Tecnologia., campus de Presidente Prudente. E-mail: bendrath@ig.com.br
} 
advocated by Anthony Giddens. It was observed indications of approximation between both policies, strengthening the educational discourse of a global panorama aligned to the flow of economic development.

Keywords: Third Way. Liberalism. International Politics. Education.

\section{Introdução}

As concepções do termo "ideologia" podem fundamentar-se nas bases do senso comum através do ideário da "perfeição" a ser atingida, ou na possibilidade de compreensão inversa do termo, tendo como interpretação o processo de persuasão, de dominação. Dessa forma o contexto de sua aplicação define de qual maneira seu emprego pode ser considerado mais adequado dentro da sociedade. Marx concebia a ideologia como sistema de pensamento e relações sociais, produzido pelos homens em relação as suas atividades.

A ideologia da Terceira Via, enunciada no título do trabalho, chama a atenção para uma corrente que tenta se distanciar dos movimentos políticos e econômicos que predominantemente foram base de sustentação dos países ocidentais e orientais nas últimas décadas, e que, com o movimento de globalização latente, não oferecem respostas efetivas aos problemas decorrentes da internacionalização dos processos e produtos. Tal ideologia pode então, a partir da visão interpretativa escolhida, ser um construto para atingir a perfeição ou a dominação. $\mathrm{O}$ movimento educacional segue o mesmo paradoxo, e apresenta indicativos de adequação às concepções políticas vigentes, dentre elas, o formulado pelos teóricos da Terceira Via.

Dessa forma o objetivo central desse trabalho foi o de apresentar indicativos de reflexão para as abordagens políticas que tomam o panorama econômico global como fundamento de reformas educacionais, com especial atenção ao discurso oficial de organismos internacionais e sua direta influência nas tomadas de decisões dos governos. Como procedimento de compreensão desse panorama tomou-se como referência uma análise documental e bibliográfica sobre a temática, estabelecendo um diálogo a cerca das inferências expostas nas documentações oficiais da UNESCO (2001 e 2008) e da publicação por ela apoiada do Relatório da Comissão Interna- cional para Educação no século XXI (DELORS, 1996), em relação à sua articulação política direta com o discurso teórico da Terceira Via (GIDDENS, 1996; 2001). Também foram incorporadas leituras de autores críticos ao modelo proposto pela Terceira Via como ferramenta de interposição e compreensão geral da abordagem teórica.

Justifica-se essa análise a partir da necessidade de compreensão do alinhamento das estruturas educacionais ao fluxo econômico mundialmente globalizado. Tal entendimento se faz necessário na medida em que sua influência impacta na sociedade a cada nova configuração mundial, exercendo um papel decisivo no avanço, estagnação ou retrocesso dos processos de desenvolvimento econômico e social, refletindo diretamente nos objetivos e fins da educação. Assim como as reformas econômicas e educacionais ocorridas no Pós-Guerra ${ }^{1}$ pautadas no modelo Keynesiano centralizador, e posteriormente as reformas pautadas na descentralização estatal conclamadas pelas reformas Neoliberais; as reformas e medidas oriundas pelos teóricos da Terceira Via devem obter especial atenção no momento histórico em que vivemos, pois influenciam e direcionam as decisões políticas que trilham o futuro governamental.

Nesse sentido, Giddens (2001, p.36) descreve que a Terceira Via se refere a uma estrutura de pensamento e de prática política que visa a adaptar a social democracia a um mundo que se transformou fundamentalmente ao longo das últimas duas ou três décadas. É uma Terceira Via no sentido de que é uma tentativa de transcender tanto a social democracia do velho estilo quanto o Neoliberalismo, a forma como as relações serão estabelecidas nos níveis internacionais, e de como o desenvolvimento social e econômico são abordados por essa política,

\footnotetext{
${ }^{1}$ Para maiores informações ver: BENDRATH; GOMES. Educação e Economia: A (re) construção histórica a partir do pós-guerra. HistedBr. Campinas, n.44, dez.2011, p.92-106.
} 
remetem a uma tentativa de buscar respostas para problemas que antes não existiam, e que agora convivem dentro de um conjunto geral de incertezas. A educação aparece, portanto, como um importante elemento político de manutenção da sociedade, ao tempo em que, às diretrizes educacionais encaminha-se para o direcionamento da política internacional, formando cidadãos aptos e preparados para enfrentarem os desafios da alta competitividade, da concorrência exacerbada, da vitória a qualquer custo.

Com esse contexto posto, a participação da Organização das Nações Unidas para a Educação, Ciência e Cultura (UNESCO) no delineamento das proposições educacionais em âmbito global, indica o referencial a ser seguido pelos países, tendo como principal matriz teórica o relatório da comissão internacional sobre Educação no século XXI, mais popularmente conhecido como relatório Delors publicado 1996. Giddens e Delors aparecem como idealistas de uma nova proposição ${ }^{2}$ teórica de organização dos sistemas econômicos, político e educacional no novo milênio, e suas indicações são referência para tomada de decisões de líderes globais.

\section{Um novo plano econômico e político de ação}

A última década reformulou os conceitos das teorias econômicas e políticas que até então embasaram a construção dos sistemas educacionais em nível global sob a orientação ou do capital liberal, ou do Estado centralizador. Para o rompimento das ações que fundamentam as práticas educativas do novo milênio, a sustentação de um aparato político ideológico surge com a perspectiva de modificar conceitos e proposições: a Terceira Via.

Tendo como um de seus idealizadores o sociólogo inglês Anthony Giddens, a Terceira Via pode ser considerada a partir de uma leitura mais crítica como um "social-liberalismo" (LIMA, MARTINS, 2005). Seu pressuposto se baseia na reformulação de governos e políticas vigentes, tendo como pano de fundo o aparato social do Estado de um lado, e a

\footnotetext{
${ }^{2}$ Alguns intelectuais consideram as proposições dos autores, cada um em seu campo, como aperfeiçoamentos de regimes e sistemas já existentes anteriormente, porém com alterações no modo de desenvolvimento e aplicação dos mesmos.
}

livre concorrência de mercado de outro. Apesar da crítica ao movimento ortodoxo do neoliberalismo, especialmente a questão do Estado mínimo, a desregulamentação e o individualismo econômico, Lima e Martins (2005), destacam que os teóricos da Terceira Via acreditam que algumas medidas tomadas por países tendo como referência o modelo neoliberal, "foram atos necessários".

Dessa maneira, o capitalismo pode ser considerado um fator de integração em determinadas circunstâncias, pois, como afirma Saul (2003, p.142)

O capitalismo contemporâneo é visto por Giddens como um novo modelo de integração social, orientado por laços que se estendem muito além das fronteiras tradicionais das comunidades e das nações, levando em si um novo sentido de organização social e política que desafia as atuais gerações a repensarem as raízes da experiência democrática. Este é o sentido de A terceira via. E também o sentido da teoria social de Giddens. (SAUL, 2003, p.142)

O Estado a partir dessa concepção deve ser capaz de organizar os sistemas internos de ações sociais, ao mesmo tempo em que deve garantir o acesso ao mercado no plano nacional e internacional. Distanciando-se de uma posição centralizadora, de um Estado de Bem Estar Social (welfare state), conclamado por Keynes a partir da concentração das ações estatais dentro do conceito de Estado provedor, a Terceira Via advoga a co-responsabilidade do desenvolvimento social entre entidades públicas e privadas.

Bendrath e Gomes (2010) relatam que o modelo Keynesiano de um Estado do Bem Estar Social, pautado no conservadorismo econômico, não foi capaz de garantir em longo prazo os direitos sociais e a garantia de pleno emprego, gerando um crescimento do custo estatal além do esperado. As criticas oriundas dos neoliberais, enfatizavam a necessidade de abertura comercial, a desregulamentação do custeio estatal (Estado mínimo) e o equilíbrio econômico pautado nas leis de mercado.

Essa noção proposta de realinhamento das ações políticas direciona ao que Giddens (2001) denomina de governabilidade do novo Estado democrático. Assim agências nacionais e transnacionais, bem como o setor privado, devem contribuir para o processo de tomada de decisões. 
Os intelectuais adeptos das teorias da Terceira Via, entendem que o mundo na qual vivemos atualmente não deve ser configurado tendo como parâmetros apenas os processos de construção histórica da sociedade, ele deve ser encarado como um mundo de incertezas, onde as constantes alterações da realidade constituem significativas modificações no campo político.

A intromissão da incerteza artificial em nossas vidas não significa que nossa existência, em um nível coletivo ou individual, seja mais arriscada do que costumava ser. Ao contrário, as fontes e a abrangência do risco mudaram. O risco individual (manufactured risk) é um resultado da intervenção humana nas condições da vida social e da natureza. As incertezas (e oportunidades) que ele cria são bastante novas. (GIDDENS, 1996, p.12)

Ao tentar romper com os movimentos dicotômicos polarizados em liberalismo e socialismo, Giddens tenta retratar a sociedade a partir de um novo pressuposto que não ignora a contribuição de ambos os modelos no desenvolvimento da sociedade. Sua visão centra-se na redistribuição do conceito de sociedade contemporânea, onde as constantes alterações no modo de vida e no modo de produção e acumulação do capital interferem diretamente nos sistemas de governo.

Nesse contexto, a participação da sociedade no processo de tomada de decisões seria fator fundamental para a construção de um novo processo democrático. Para Lima e Martins (2005), a Terceira Via entende que o novo Estado democrático deveria estar aberto [...] incentivando e aprofundando o surgimento de novas organizações por intermédio da definição de espaços de participação direta na aparelhagem estatal. Essa iniciativa é denominada por Gidden (1996), de democracia dialógica. Ainda de acordo com o autor, o surgimento de novas organizações, teria por objetivo criar a confiança ativa por meio de uma avaliação da integridade do outro, a confiança é um meio de ordenação das relações sociais no tempo e no espaço (GIDDENS, 1996, p.133).

No entanto, Lima e Martins (2005), relatam que é necessário considerar que um processo efetivo de emancipação coletiva do homem só ocorrerá quando esses movimentos, mantidas suas identidades e especificidades, forem capazes de convergir seus interesses em torno de um projeto maior, que envolva a vontade coletiva majoritária.

Saul (2003) relata a dificuldade em estabelecer um panorama de como o processo de governo será aplicado tendo diferentes atores no contexto político.

É difícil estabelecer com clareza quais as funções do Estado ou do governo, pois que o uso das noções se alternam e se confundem, não permitindo a identificação de instâncias de poder diferenciadas, ou mesmo ações relacionadas com a atividade de governar. Assim, por exemplo, ao encaminhar o problema da renovação da sociedade civil, dentro da ótica da terceira via, o conceito de governo aparece confundido com a idéia de ação de governar. (SAUL, 2003, p.151)

A teoria do capital humano, proposto por Theodore Schultz na década de 1960, reintegra de forma objetiva os pressupostos da Terceira Via, tendo em vista que o conceito de eficiência e produtividade estão, para Schultz, associados diretamente a esse capital humano. Descartam-se, dessa maneira, as relações históricas estabelecidas entre sujeitos e classes, atribuindo ao capital humano, as diferenças entre empresas e países. De posse dessa afirmação, é proposto por tanto que todos sejam capitalistas: alguns por serem os proprietários dos meios de produção, e outros por serem proprietários do capital humano. Dentro dessa concepção chega-se a impressionante conclusão: no capitalismo não existem classes sociais. (LIMA, MARTINS, 2005, p.62)

$\mathrm{Na}$ nova agenda internacional, as ações de nível global vêm sendo construídas ao longo dos últimos anos tendo as organizações multilaterais e internacionais, papel decisivo no direcionamento das políticas públicas. Agências como o Banco Mundial (BM), Organização das Nações Unidas (ONU), Fundo Monetário Internacional (FMI) e Organização das Nações Unidas para a Educação, Ciência e Cultura (UNESCO), participam ativamente das discussões políticas no campo da economia e desenvolvimento social em nível transnacional, influenciando a tomada de decisões onde estão inseridas.

Para o movimento da Terceira Via, os organismos internacionais possuem papel decisivo na política considerando-se o fenômeno da globalização. Porém os conceitos atribuídos à teoria do capital humano recebem outra roupagem quando o discurso 
é proferido por esses organismos. De acordo com Lima e Martins (2005, p.62-63), o “capital social” é empregado nos discursos oficiais, especialmente difundidos pela corrente intelectual norte-americana, remetendo à capacidade de articulação dos grupos de pessoas ou de toda uma comunidade local, nas busca de solução de seus problemas mais imediatos. Ela é utilizada junto às noções de pobreza e de desenvolvimento social sustentado para orientar a definição das políticas sociais neoliberais focalizadas.

A partir dessa perspectiva, a formação do "capital humano" e do "capital social", reforça a necessidade de articulação entre agências internacionais, países e comunidade, no sentido de garantir a plena adequação às necessidades globais de desenvolvimento. A educação, portanto, passa a ser elemento fundamental na articulação dessas ações. Bendrath e Gomes (2010) afirmam que, através de tais proposições, os modelos de políticas públicas adotados pelos Organismos Internacionais tendem a favorecer movimentos educacionais que fogem da rigidez e burocracia estatal, ampliando o acesso da sociedade a projetos, por exemplo, de educação não-formal.

Nesse sentido, Lima e Martins (2005), colocam que uma das estratégias educacionais da Terceira Via consiste na promoção de um novo pacto social, com a criação de novos sujeitos políticos coletivos, eliminando as restrições sociais de ordem burguesa, disseminando valores a essa doutrina. Assim a participação de organismos internacionais estaria focalizada no suporte pedagógico à aparelhagem estatal, oferecendo o Know How no processo de implantação e gerenciamento de programas e projetos paralelos ao processo formal de ensino. Nesse contexto, Bendrath e Gomes (2010) destacam que a influência partindo de organismos internacionais, não mais que remete a indicações de natureza técnica/operacional sobre determinado foco.

\section{Educação e Política Internacional}

Do ponto de vista da construção da ordem internacional, portanto, uma grande dificuldade reside na relutância dos Estados em ceder parte de sua soberania em favor de instâncias internacionais porque, inevitavelmente, essa atitude significa abrir mão, total ou parcialmente, da prerrogativa de transformar em ação política suas visões e percepções acerca do mundo e das coisas. (SATO, 2003, p.163)

A grande questão que está posta nos dias atuais, faz menção a como a educação da sociedade será tratada em meio à efervescência da globalização, e de que forma a formação humana pode efetivamente contribuir para a manutenção desse status quo. A participação de organismos internacionais no direcionamento de políticas econômicas e sociais em países em desenvolvimento esbarra principalmente na questão da soberania do Estado discutido por SATO (2003). Uma das maneiras de atuar diretamente nas frentes políticas, portanto, concretizou-se com a assinatura de acordos e tratados internacionais de prazos e metas.

Sato (2003) define que as organizações internacionais são as expressões mais visíveis dos esforços de cooperação internacional de forma articulada e permanente. Porém tomando como referência o desenvolvimento social como eixo fundamental, nos interessa saber, a quem interessa esse esforço de cooperação internacional quando a ordem política econômica vigente favorece a especulação internacional enfraquecendo o poder do Estado? Nesse sentido, a educação é, portanto, um fator determinante na política internacional, e a sua diretriz macro é um importante elemento de verificação dos rumos que se seguem.

De acordo com Giddens (2001), a formação intelectual, moral, ético-política e técnica ao longo de toda a vida das pessoas, devem ser dadas com ênfase no desenvolvimento de competência cognitiva e emocional. Tal premissa, sustentada nas bases da Terceira Via, adequa-se irrestritamente ao que proclama a UNESCO a partir do relatório Delors de 1996. O relatório Delors, intitulado "Educação um tesouro a descobrir", define o conceito de educação do novo milênio, atentando a sociedade e os Estados, a pensarem a educação ao longo de toda a vida, tendo como princípios uma concepção voltada para o desenvolvimento de habilidades e competências necessárias na sociedade moderna. Tais competências e habilidades voltam-se para as expressões técnicas e pessoais de adequação à sociedade capitalista, onde a acumulação de capital e a formação humana seriam sinônimos de prosperidade. 
Para Delors (1996) o mal-estar causado pela falta de visão clara do futuro, conjuga-se com a consciência cada vez maior das diferenças existentes no mundo, e das múltiplas tensões que daí resultam, entre o "local" e o "global", uma leitura precisa da definição de Giddens (2001) sobre a necessidade de romper-se com os modelos de políticas vigentes, propondo-se uma Terceira Via, que processará as diferentes manifestações das incertezas artificiais que geram as alterações políticas, e que afetam toda a sociedade.

A UNESCO pode contribuir muito, através da educação, para a abertura dos espíritos, aos deveres da solidariedade internacional. Agora que as organizações internacionais e as nações se preparam para os grandes desafios do século XXI a cidadania mundial continua a ser um conceito muito afastado das realidades e percepções concretas. (DELORS, 1996, p.207)

Lima e Martins (2005) advogam que a Terceira Via propõe que o Estado assuma seu papel pedagógico fundamental de impulsionar uma nova cultura cívica por meio da renovação organizativa da sociedade civil, visando a consolidar a coesão social. Essa relação de auxílio mútuo entre os deveres do Estado e o auxílio de um agente internacional é apresentado por Delors (1996, p.207), ao afirmar que a UNESCO é uma entidade competente para auxiliar os Estados a construir e renovar ${ }^{3}$ seus sistemas educativos.

Gewirtz (2002) relata em seu artigo as conseqüências educacionais da implantação da política da Terceira Via no sistema educacional inglês. Segundo a autora, o governo do New Labour na Grã-Bretanha, tal como aconteceu em muitos outros países europeus, assumiu as perspectivas da 'Terceira Via' relativamente à governação do setor público, seu impacto, portanto, também ocorreu no sistema educacional.

Para Gewirtz (2002, p.123), as principais alterações ocorridas no sistema educacional da Grã-Bretanha foram:

- Os processos de mercadorização foram assumidos e reforçados. Os recursos foram distribuídos às escolas primeiramente

\footnotetext{
${ }^{3}$ Destaque do autor
}

numa base per capita e não com base nas necessidades, e assistimos a uma maior 'diversificação' da 'escolha' do mercado através da expansão do programa de escolas especializadas.

- A privatização foi ampliada, através da expansão da Iniciativa do Financiamento Privado (Private Finance Initiative - PFI) e através do aumento das oportunidades de negócio na gestão das escolas e no fornecimento de serviços das autoridades educacionais locais (Local Education Authority - LEA).

- Houve uma intensificação do "managerialismo" na educação. Por outras palavras, houve uma intensificação das tentativas de aplicar as práticas de gestão, pedidos de empréstimo às empresas para gestão das escolas. Isto foi evidenciado pela introdução de políticas desenhadas para promover o estabelecimento de objetivos e a monitorização do desempenho nas escolas e nas LEA, pela introdução do pagamento referido ao desempenho e ao desenvolvimento da utilização da competição como um mecanismo para distribuir recursos às escolas e às LEA.

- Assistimos uma maior 'economização' do currículo escolar. Houve tentativas de articular mais estreitamente as supostas necessidades da economia, através da introdução de mais aprendizagens ligadas ao trabalho.

- E finalmente assistimos a um maior grau de controle central do ensino e da aprendizagem, como ficou evidenciado na introdução de estratégias nacionais, relativamente à literacia e à numeracia e na promoção do estabelecimento de aptidões nas escolas.

Verifica-se no discurso de Gewirtz, que, apesar de uma medida de Estado, a aplicação de uma política educacional pautada no conceito da Terceira Via segue um delineamento internacional. A indicação de "processos de mercadorização" é estipulada com base em tetos orçamentários de gastos públicos com sistemas educacionais, tal qual os definidos pelo Banco Mundial e Fundo Monetário Internacional relatados por Haddad (2008). Outro 
exemplo citado, o processo de "economização", pauta-se nos pressupostos definidos por Delors (1996)

Ora, muitas vezes, pensa-se que incluir na educação situações de trabalho é colocar-se numa situação de perigosa derrapagem, quando o que se pretende é melhorar a qualidade da educação. (DELORS, 1996, p.238)

A educação com vistas ao mercado de trabalho, remete ao conceito da formação do capital humano para o sistema de acumulação capitalista. Para Giddens (2000, apud Saul, 2003), a força chave no desenvolvimento do capital humano deve ser obviamente a educação. É o principal investimento público para impulsionar tanto a eficiência econômica quanto a coesão cívica.

Assim o conceito de eficiência, eficácia e efetividade social são fatores determinantes na construção e manutenção de políticas vigentes, tendo como pano de fundo o movimento da Terceira Via. A partir dessa perspectiva Delors (1996) aponta a necessidade de adequação dos sistemas de comparações internacionais com a necessidade de reformulação dos objetivos da Educação, que, para o autor, deverá estar ligado ao desenvolvimento da sociedade contribuindo para o uso de recursos que promova o crescimento econômico.

As comparações internacionais realçam a importância do capital humano e, portanto, do investimento educativo para a produtividade. A relação entre o ritmo do progresso técnico e a qualidade da intervenção humana torna-se, então, cada vez mais evidente, assim como a necessidade de formar agentes econômicos aptos a utilizar as novas tecnologias e que revelem um comportamento inovador. Requerem-se novas aptidões e os sistemas educativos devem dar resposta a esta necessidade (DELORS, 1996, p.71)

Dessa forma, a atuação de organismos internacionais pode direcionar de que maneira a formação humana poderá ser compreendida em território global, tendo como referência os pressupostos de desenvolvimento definidos pela política da Terceira Via.

Ainda segundo Delors (1996), os governos e os organismos internacionais tentaram vencer os desafios do desenvolvimento orientando, cada vez mais, a sua ação para a expansão das possibilidades da educação, contudo, essa expansão não pode acontecer sem diretrizes e processos avaliativos que possam garantir a efetividade dessa política. A partir desse panorama, o surgimento de sistemas de avaliação educacional internacional, tal qual o $\mathrm{PISA}^{4}$, e metas de cumprimento de prazos como os definidos pela UNESCO para $2015^{5}$, apresentam claramente o alinhamento entre política educacional de um lado, e política econômica de outro, a partir de um plano internacional.

\section{Considerações Finais}

A tentativa de construção de uma nova proposta teórica que vise romper com o dicotomismo polarizado entre liberalismo e socialismo naufraga nas idéias de Giddens ao verificar o cunho político de direita, pautado nos pressupostos do neoliberalismo. Com a inclusão de temas sociais, recorrentes nas camadas da sociedade civil, a Terceira Via reconfigura a estrutura lógica do modelo neoliberal, oferecendo à sociedade uma resposta imediatista aos seus anseios, porém com uma definição de objetivos estruturados na sociedade burguesa e na divisão de classes. A educação é vista, portanto, dentro dessa lógica, como uma ferramenta de construção do capital humano.

A redução da categoria histórica do trabalho, para termos genéricos e superficiais como emprego ou empregabilidade, tal qual o definido por Giddens, transforma os indivíduos em meras ferramentas a serviço das classes hegemônicas, detentoras dos bens e meios de acumulação do capital. Assim, a Terceira Via, compreende a educação como fator decisivo na construção de um sujeito acrítico, apolitizado, mas com concreta formação

\footnotetext{
${ }^{4}$ PISA significa Programme for International Student Assessment, e é um programa internacional de avaliação de estudantes proposto pela Organização para a Cooperação e Desenvolvimento Econômico (OCDE).

${ }^{5}$ O Relatório de Monitoramento Global da Educação da UNESCO, publicado em 2008, definiu o ano de 2015 como meta final para os países melhorarem seus indicadores educacionais nas áreas de alfabetização, igualdade de gênero, universalização do ensino, entre outros temas. Maiores informações: UNESCO. Relatório de Monitoramento Global. Educação para todos em 2015; alcançaremos a meta? - Brasília : UNESCO, 2008.
} 
e conhecimentos voltados para o desenvolvimento de competências e habilidades, que lhes serão extramente úteis na aplicação de suas atividades empregatícias a bem do serviço do capital. Tal prerrogativa é forte indício da aplicação globalizada de medidas de cunho hegemônico de influência direta em setores econômicos e sociais em todos os cantos do planeta. Com uma constante adequação dos modelos econômicos frente às crises pontuais e cíclicas do capitalismo, a Terceira Via apresenta a melhor roupagem para essa adequação ao tempo que, remodela seus pressupostos tendo o aspecto social forte apelo popular.

Ao aplicar os conceitos sociais em seus estudos, os teóricos da Terceira Via, direcionam as medidas emergenciais de cunho social como importante ferramenta para manutenção da sociedade a partir de suas necessidades, porém suas ações podem ser pontualmente definidas como emergenciais e compensatórias, não transformando a realidade social, mantendo os problemas latentes a um nível de controle sem, contudo, os extinguir. Programas educacionais compensatórios ${ }^{6}$ são exemplos claros dessa política, que não visa equacionar os problemas, e sim, mantê-los sob controle político garantindo créditos positivos da opinião pública.

A política pautada nos movimentos teóricos da Terceira Via, visualizam nos organismos internacionais uma parceria possível e necessária na condução da sociedade para um futuro "próspero". Tal parceria pauta-se no estabelecimento de consensos gerais, aplicáveis de forma universal, que em vias de fato, servem como régua para mensurar e classificar os países em seus inúmeros e mais variados sistemas de ranking, construindo dessa forma, uma divisão de classes em nível mundial.

Por fim, considero as proposições educacionais da Terceira Via, como uma ideologia liberal reformulada, garantindo acesso irrestrito à escola, que possui sob seus domínios, as fundamentações e postulados de uma formação com vistas ao desenvolvimento educacional do capital humano e social, tal qual o previsto e idealizado no sistema capitalista clássico.

\section{Referências}

BENDRATH, Eduard Angelo; GOMES, Alberto Albuquerque. Educação e Economia: A (re) construção histórica a partir do pós-guerra. HistedBr. Campinas, n.44, dez.2011, p. 92-106.

. Estado, Políticas Públicas e Organismos Internacionais: A Educação no foco do debate. Intermeio. Campo Grande, MS, v.16, n. 32, 2010, p.157-171.

CASSASSUS, Juan. A Reforma Educacional na América Latina no Contexto da Globalização. Cadernos de Pesquisa. n.114. Novembro 2001, p.7-28

DELORS, Jacques. Educação um tesouro a descobrir. Relatório para a UNESCO da comissão internacional sobre Educação para o século XXI. São Paulo: Cortez, 1996, 288p.

GEWIRTZ, Sharon. Alcançando o sucesso? Reflexões críticas sobre a agenda para a educação da "Terceira Via" no New Labor. Currículo sem fronteiras. v.2, n.1, 2002, p.121-139.

GIDDENS, Anthony. A terceira via: reflexões sobre o impasse político atual e o futuro da social-democracia. 4.ed. Rio de Janeiro. Record, 2001.

Para além da esquerda e da direita. $O$ futuro da política radical. São Paulo. Edunesp, 1996.

HADDAD, Sérgio et al. Banco Mundial, OMC e FMI: o impacto nas políticas educacionais. São Paulo: Cortez Editora, 2008, 214p.

LIMA, Kátia Regina de Souza; MARTINS, André Silva. Pressupostos, Princípios e Estratégias. In. NEVES, Lúcia Maria Wanderley (org.). A Nova Pedagogia da Hegemonia. Estratégias do capital para educar o consenso. São Paulo. Xamã, 2005, 312p.

SAUL, Renato P. Giddens: da ontologia social ao programa político, sem retorno. Sociologias, Porto Alegre, ano 5, n. 9 , 2003, p.142-173.

SATO, Eiiti. Conflito e cooperação nas relações internacionais. As organizações internacionais no século XXI.

Revista Brasileira de Política Internacional. n. 46 (2). 2003, 161-176p.

UNESCO. Relatório de Monitoramento Global. Educação para todos em 2015; alcançaremos a meta? - Brasília: UNESCO, 2008.

. Educação Para Todos: o compromisso de Dakar. Brasília, DF: Ação Educativa, 2001. 70 p.

Data de Submissão: maio de 2012

Data de Aprovação: dezembro de 2012

${ }^{6}$ Podemos citar como exemplo os Programas Escola da Família e Programa Bolsa Universidade do governo paulista, e os Programas Escola Aberta e PROUNI do governo federal. 